\title{
Defining and Diagnosing Postpartum Clinical Endometritis and its Impact on Reproductive Performance in Dairy Cows
}

\author{
S. J. LeBlanc, ${ }^{*}$ T. F. Duffield, ${ }^{*}$ K. E. Leslie, ${ }^{*}$ \\ K. G. Bateman, ${ }^{\star}$ G. P. Keefe, $\dagger$ \\ J. S. Walton, $\neq$ and W. H. Johnson* \\ *Department of Population Medicine and \\ ‡Department of Animal and Poultry Science \\ University of Guelph, \\ Guelph, Ontario, Canada N1G 2W1 \\ †Department of Health Management \\ University of Prince Edward Island, \\ Charlottetown, Prince Edward Island, Canada C1A 4P3
}

\begin{abstract}
The objectives of this study were to validate diagnostic criteria for clinical endometritis in postpartum dairy cows and to measure the impact of endometritis on reproductive performance. Data were collected from 1865 cows in 27 herds, including history of dystocia, twins, retained placenta, or metritis. All cows were examined once between 20 and $33 \mathrm{~d}$ in milk (DIM) including external inspection, vaginoscopy, and transrectal palpation of the cervix, uterus, and ovaries. All cows were followed for a minimum of $7 \mathrm{mo}$ or until pregnancy or culling. Survival analysis was used to derive a case definition of endometritis based on factors associated with increased time to pregnancy. The significance of clinical findings depended on the interval postpartum when examination took place. The presence of purulent uterine discharge or cervical diameter $>7.5 \mathrm{~cm}$ after 20 DIM, or mucopurulent discharge after 26 DIM identified cows with clinical endometritis. Given vaginoscopy, no diagnostic criteria based on palpation of the uterus had predictive value for time to pregnancy. The prevalence of clinical endometritis was $16.9 \%$. Vaginoscopy was required to identify $44 \%$ of these cases. Accounting for parity, herd, and ovarian status, cows with clinical endometritis between 20 and 33 DIM had a hazard ratio of 0.73 for pregnancy (took $27 \%$ longer to become pregnant), and were 1.7 times more likely to be culled for reproductive failure than cows without endometritis.
\end{abstract}

(Key words: endometritis, diagnosis, pregnancy rate, vaginoscopy)

Received November 22, 2001.

Accepted February 3, 2002.

Corresponding author: S. LeBlanc; e-mail: sleblanc@ovc. uoguelph.ca.
Abbreviation key: $\mathbf{C L}=$ corpus luteum, $\mathbf{H R}=$ hazard ratio, $\mathbf{O R}=$ odds ratio.

\section{INTRODUCTION}

The goal of reproduction management in dairy cattle is to have cows become pregnant in an efficient manner and at a profitable interval after calving (Dijkhuizen et al., 1985; Plazier et al., 1997). Although there are many causes of reproductive inefficiency in dairy cows (Radostitis et al., 1994), particularly management factors such as lack of estrus detection intensity (Ferguson and Galligan, 1999), traditional veterinary practice has focused on postpartum uterine disease. Veterinary and management reproductive interventions are only beneficial if they result in more timely pregnancy. For reproductive examinations before the breeding period to be of value, they must identify cows at increased risk of failure to become pregnant in a timely way. Moreover, this diagnostic process must identify those cows that may benefit from treatment of endometritis. A practical case definition is needed for clinical endometritis that is based on diagnostic criteria that identify cows that truly will have impaired reproductive performance.

In numerous observational studies, the terms metritis and endometritis have been used interchangeably, often without a case definition for either (Sandals et al., 1979; Erb et al., 1984, 1985; Grohn et al., 1989; Oltenacu et al., 1990; Correa et al., 1993; Emanuelson, 1993). As a pathologic entity, endometritis is an inflammation of the endometrial lining of the uterus without systemic signs, which is associated with chronic postpartum infection of the uterus with pathogenic bacteria, primarily Arcanobacterium pyogenes (Lewis, 1997; Bondurant, 1999). Clinically, the challenge is to identify those cows that are truly at risk of impaired fertility, in the hope that treatment can be administered to correct the problem. While the morphologic definition 
of this pathology is conceptually important, a clinically useful case definition and diagnostic criteria are needed.

The most common means of diagnosis of endometritis is transrectal palpation of the uterus. However, this method is subjective and often fails to account for normal events and variability in uterine involution (Morrow et al., 1966; Gier and Marion, 1968) or to have any association with reproductive performance (Studer and Morrow, 1978; Miller et al., 1980; Lewis, 1997). The results of vaginoscopy are more strongly associated with bacterial infection (Miller et al, 1980; Dohmen et al., 1995), yet this tool is not commonly employed. Postpartum endometrial biopsies have been shown to have predictive value for reproductive performance, but the technique itself is associated with deleterious effects on fertility (Bonnett et al., 1993). Well-designed, appropriately analyzed, large-scale field studies of the diagnosis of endometritis with both an objective case definition and economically meaningful outcomes are lacking (Gilbert and Schwark, 1992).

The objectives of this study were to investigate and validate diagnostic criteria for clinical endometritis, derive a clinically useful case definition for endometritis based on factors that are predictive of time to pregnancy, and assess the impact of endometritis on reproductive performance and culling in dairy cows.

\section{MATERIALS AND METHODS}

\section{Study Subjects}

The study was conducted in a convenience sample of 27 dairy herds, including 21 in southwestern Ontario and six on Prince Edward Island, Canada. The study population consisted of lactating Holstein cows in typical central and eastern Canadian commercial dairy herds, including seven free-stall and 20 tie-stall barns. Herd size ranged from 30 to 230 milking cows. All cows took part in a clinical trial for therapy of endometritis (LeBlanc et al., 2002) concurrent with the present study. All herd managers agreed not to administer any intrauterine or reproductive hormonal therapy before examination of cows for this trial.

Each postpartum cow and heifer in the study herds was examined once between 20 and 33 d postpartum, inclusive, at a biweekly herd visit. Individual cow parity group (first, second, or third and greater) and season of calving (Fall: September through November; Winter: December through February; Spring: March through May; Summer: June through August) were recorded. Occurrences of veterinary-assisted calving, twins, retained placenta (failure to pass the fetal membranes by $24 \mathrm{~h}$ after parturition), or metritis (uterine infection producing systemic illness) in the current lactation were also recorded.

At examination, cows were first inspected for the presence of fresh discharge on the vulva, perineum, or tail. If discharge was not visible externally, cows were examined vaginoscopically. The vulva was wiped clean with damp paper towels, and lubricant was applied to a disposable $50-\mathrm{cm}$, foil-lined cardboard vaginoscope. The vaginoscope was inserted into the vagina up to the level of the external os of the cervix. Inspection of the cervix and vagina was performed with illumination from a penlight. The examination lasted for 5 to $30 \mathrm{~s} /$ cow. The nature of discharge was classified as clear mucus, predominantly clear mucus with flecks of pus, mucopurulent (approximately 50\% pus and 50\% mucus), purulent ( $>50 \%$ pus) but not foul-smelling, or purulent or red-brown and foul smelling. The location and character of discharge were recorded. No attempt was made to quantify the volume of discharge.

Following inspection and vaginoscopy, transrectal palpation of the reproductive tract was performed and findings were classified as follows:

- Cervical diameter $(<5 \mathrm{~cm}, 5$ to $7.5 \mathrm{~cm},>7.5 \mathrm{~cm})$,

- Location of the uterus (entirely within the pelvis, or over the pelvic brim but completely palpable after retraction, or over the pelvic brim and not completely palpable),

- Symmetry of the uterine horns (yes or no),

- Diameter of the (larger) uterine horn (in $\mathrm{cm}$ ),

- Texture of uterine wall (thin or thick),

- Palpable uterine lumen (yes or no),

- Dominant palpable ovarian structure [corpus luteum (CL), follicle, cyst ( $>2.5 \mathrm{~cm}$ in diameter), or no palpable structures. When more than one structure was present, the order of dominance was cyst, CL, then follicle].

To standardize the reporting of clinical findings, a centimeter scale was provided on the data-recording forms. Additionally, at the start of the study all participating clinicians received standard instruction on the method of data collection.

At the conclusion of the clinical examination, cows were assigned at random to receive one intrauterine infusion of $500 \mathrm{mg}$ of cephapirin benzathine (Metricure, Intervet, Whitby, Ontario), or one intramuscular injection of $500 \mu \mathrm{g}$ of cloprostenol (Estrumate, ScheringPlough, Pointe Claire, Quebec), or no treatment. The details of the treatment protocol and its effects are reported elsewhere (LeBlanc et al., 2002). Possible confounding effects of treatment in the present analysis were controlled analytically. Animals were excluded or withdrawn from the study if they had any of the following: clinical disease requiring systemic treatment at enrollment; systemic antibiotic therapy in the $7 \mathrm{~d}$ before 
enrollment; intrauterine therapy or reproductive hormone administration in the current lactation before enrollment; pyometra at enrollment (uterine horn distended with fluid in the presence of a CL, diagnosed by palpation); or adhesions involving the internal genitalia.

Following the clinical assessment period, all cows followed the normal herd reproductive management practices in the breeding period. This included various individual and systematic herd programs for estrous detection or synchronization, or synchronization of ovulation. Insemination and culling dates were collected using on-farm data-recording forms and data from DHI records. Reproductive performance and culling data on individual animals were collected for a minimum of 7 mo after enrollment. Observations of time to pregnancy were censored for nonpregnant cows on the date of culling or at the end of the study, 7 mo after the last cow was enrolled.

The following outcomes were measured to assess reproductive performance: interval from calving to first insemination (days to first service), first service pregnancy risk (\%), interval from calving to pregnancy (days open), cumulative pregnancy risk (\%), number of inseminations for pregnant cows, and removal risk for reproductive failure (\%). Pregnancy was diagnosed by transrectal palpation of the uterus at least $35 \mathrm{~d}$ postbreeding. Cumulative pregnancy risk was the proportion of cows enrolled in the trial that eventually became pregnant in that lactation. Removal risk for reproductive failure was the proportion of cows enrolled in the trial that were inseminated at least three times but did not become pregnant and were culled.

\section{Data Management and Statistical Methods}

All analyses were performed with SAS, Version 8.0 (SAS Inst., Inc., 1999) with the cow as the unit of concern. Because many of the variables examined were expected to be dynamic over the enrollment period, it was decided a priori to examine findings stratified into the earlier (20 to $26 \mathrm{DIM}$, inclusive) and later (27 to 33 DIM, inclusive) halves of the period, as well as overall. Models of dichotomous outcomes were generated using multivariable logistic regression (the GENMOD procedure in SAS, with binomial distribution and the logit link function). Biologically plausible interactions between significant covariates and endometritis were examined. A log-linear model was used for the count of inseminations in pregnant cows using the GENMOD procedure in SAS, but specifying a Poisson distribution, log link, and offset equal to the natural logarithm of the number of cows in each stratum. The effect of correlation of cows within herd (clustering) was adjusted for in both the binary and count models using generalized estimating equations (GEE) with compound symmetry correlation structure to produce robust standard errors (McDermott et al., 1994; Shoukri and Pause, 1999).

Time to first breeding and time to pregnancy were analyzed with multivariable survival analysis using Cox's proportional hazards regression (the PHREG procedure in SAS; Collett, 1994). To verify the assumption of proportional hazards of pregnancy for cows with and without endometritis, the data were stratified by endometritis status, and Kaplan-Meier survival functions were estimated for each group using the LIFETEST procedure in SAS. The $-\log [\log$ (Survival function) $]$ for each stratum was plotted against the natural logarithm of time to pregnancy, and the curves were confirmed to be parallel by inspection (Collett, 1994). Correlation of cows within herd was accounted for with the proportional hazards leverage (PHLEV) macro in SAS (Bergstralh et al., 1993; Therneau, 1993). There is no method available currently to account or correct for nonrandom censoring in survival analysis. Therefore, to the extent that censoring may be directly related to endometritis, bias might be present.

Although survival analysis models time to an event, in Cox's model, the output is expressed as a hazard ratio (HR) or instantaneous relative risk of pregnancy between groups in a very small time interval. Because these risks are constantly proportional, the output may be interpreted as the relative "daily probability of conception" (Fourichon et al., 2000) or relative pregnancy rate (speed at which cows become pregnant). KaplanMeier survival function estimates (the LIFETEST procedure in SAS) were used to calculate crude median days open and to generate graphs of cumulative pregnancy risk over time using spline curve-fitting in Sigma-Plot (Version 5.0, SPSS Inc., 1999). Median days open, adjusted for significant covariates, were taken from the survival function estimates produced by the PHREG baseline option, at the point where the survival function estimates stabilized below 0.5.

\section{Case Definition for Clinical Endometritis}

All variables describing history, inspection, vaginoscopy, discharge score, and findings on rectal palpation, as well as parity group and season of calving covariates, were offered to proportional hazards regression models of time to pregnancy. Preliminary screening of variables using contingency tables indicated that the thresholds of cervical diameter $>7.5 \mathrm{~cm}$ and uterine horn diameter $\geq 8 \mathrm{~cm}$ were significantly associated with pregnancy by 120 DIM. The effect of treatment (dummy variables for infusion or $\mathrm{PGF}_{2 \alpha}$, relative to controls) was controlled by forced inclusion in all models. Additionally, a model 
of diagnostic criteria for endometritis was built using only the cows that received no treatment. All models accounted for herd clustering with GEE or PHLEV, as appropriate. Models were built by manual backward stepwise elimination. At each step, the one variable with the highest $P$ value was removed and the model run again until all remaining independent variables and covariates were significant at $P<0.10$. In stratified models, significant covariates from the overall model were retained to avoid confounding. Initially, the overall effect of presence or absence of purulent discharge was examined. Models to refine the effect of discharge based on the means by which it was identified were built by creating dummy variables for discharge found on inspection, and discharge found by vaginoscopy, with no pus discharge as the referent. Similarly, dummy variables were created for each classification of purulent discharge, relative to the combined category of no discharge or clear mucus. Additionally, Walter's hierarchical dummy variables were created for each level of discharge score relative to the one below, again with the combined category of no discharge or clear mucus as the baseline. The approach taken was first to model the overall effects of clinical findings, then to refine the effect of how discharge was identified (inspection or vaginoscopy) and the character of the discharge, and finally to examine effect modification of the significant findings by the interval postpartum at which they were found (20 to 26 DIM or 27 to 33 DIM). Additionally, models were built to examine the effect of using history, external inspection and palpation, but ignoring vaginoscopy to diagnose clinical endometritis.

Once the final data-derived case definition for clinical endometritis was established, risk factors for endometritis and the impact of endometritis on reproductive performance were modeled as described above. For the analysis of prior reproductive events as risk factors for endometritis, only data from herds where reporting was known to be complete ( $\mathrm{n}=1292$ cows $)$ were used. The effect of endometritis was estimated in models of the reproductive outcomes, with parity group and ovarian findings as covariates, and treatment and adjustment for intraherd correlation forced into all models. Sensitivity and specificity of the diagnostic criteria for classification of prolonged nonpregnancy were calculated (Martin et al., 1987).

\section{RESULTS}

\section{Descriptive Statistics}

The study began in July 1998, and enrollment continued until November 1999. Followup of all cows was terminated July 5,2000 . In total, 1951 cows were examined, of which $41(2.1 \%)$ were excluded from the study, including one for pyometra, 11 for adhesions and injuries of the reproductive tract, 22 because of prior or concurrent antibiotic therapy, and seven that had been identified for early culling for nonreproductive problems. Examination data from another 45 cows were incomplete, preventing classification with respect to endometritis status. Thus, 1865 cows were available for analysis. No iatrogenic injuries or infections were recorded as a result of vaginoscopy. Table 1 describes the prevalence of clinical findings relevant to endometritis. The number of cows with data on each variable of interest varied due to missing observations on the examination forms.

Almost one-third of the cows examined had some pus discharge, but only $22 \%$ of these were found by inspection of the perineum (Table 1). Between 20 and 33 DIM, the prevalence of purulent discharge was decreasing, the uterus and cervix were shrinking, and prevalence of ovarian structures consistent with resumption of cyclicity was increasing. The clinical findings were consistent with the process of involution continuing until at least 4 wk postpartum, on average.

\section{Defining Clinical Endometritis}

Endometritis was defined as those clinical findings that predicted reduced pregnancy rate. The results of modeling predictors of time to pregnancy are in Tables 2 and 3 . When all available information, including prior reproductive disorders, inspection, vaginoscopy, and all palpation data were considered together, only the presence of pus discharge and cervical diameter $>7.5 \mathrm{~cm}$ were associated with impaired fertility (Table 2). Evidence of ovarian activity (presence of a CL or follicle) was associated with increased pregnancy rate. There was no difference $(P>0.4)$ in the impact of endometritis on pregnancy rate whether discharge was found on external inspection, or by vaginoscopy. In proportional hazards survival analysis, the HR is the daily risk of pregnancy, relative to cows without the factor of interest. For example, in Table 2, $\mathrm{HR}=0.81$ means that a cow with visible discharge had a risk of pregnancy/unit of time (true pregnancy rate) $81 \%$ of that of a similar cow without discharge.

The effect of the character of discharge at the time of diagnosis was examined for its association with reproductive performance. In initial models using Walter's hierarchical dummy variables, there was no significant difference in pregnancy rate between cows with purulent or foul discharge. Therefore, these categories were collapsed into one. The three remaining categories were compared to the referent of no discharge or clear mucus. There tended to be increasing impairment of fertility with increasingly purulent discharge. How- 
Table 1. Clinical findings in Holstein cows undergoing routine reproductive examination, including inspection of the perineum, vaginoscopy, and transrectal palpation between 20 and 33 DIM.

\begin{tabular}{|c|c|c|c|c|}
\hline \multirow[b]{2}{*}{ Finding } & \multirow[b]{2}{*}{$\mathrm{n}$} & \multicolumn{3}{|c|}{ Interval postpartum at examination } \\
\hline & & 20 to 26 DIM & 27 to 33 DIM & Overall \\
\hline & & \multicolumn{3}{|c|}{ - \% of cows examined } \\
\hline Prevalence of visible pus discharge & 1865 & & & \\
\hline On external inspection & & 8.5 & 4.6 & 6.6 \\
\hline By vaginoscopy & & 29.6 & 17.1 & 23.5 \\
\hline Character of discharge & 1865 & & & \\
\hline None & & 35.2 & 46.0 & 40.5 \\
\hline Clear mucus & & 26.6 & 32.3 & 29.4 \\
\hline Mucus with flecks of pus & & 12.1 & 7.9 & 10.0 \\
\hline Mucopurulent & & 15.7 & 8.5 & 12.2 \\
\hline Purulent & & 8.8 & 4.4 & 6.6 \\
\hline Foul & & 1.6 & 1.0 & 1.3 \\
\hline Cervical diameter & 1807 & & & \\
\hline$<5 \mathrm{~cm}$ & & 42.0 & 61.9 & 51.7 \\
\hline 5 to $7.5 \mathrm{~cm}$ & & 47.9 & 34.8 & 41.5 \\
\hline$>7.5 \mathrm{~cm}$ & & 10.1 & 3.4 & 6.8 \\
\hline Location of uterus & 1786 & & & \\
\hline In pelvis & & 40.1 & 50.1 & 45.0 \\
\hline Retractable & & 55.3 & 48.4 & 51.9 \\
\hline Over pelvic brim & & 4.6 & 1.5 & 3.1 \\
\hline Symmetry of horns & 1801 & & & \\
\hline$\%$ asymmetrical & & 44.8 & 29.8 & 37.4 \\
\hline Size of (larger) uterine horn & 1595 & & & \\
\hline Mean $\pm \mathrm{SD}(\mathrm{cm})$ & & $5.3 \pm 2.1$ & $4.4 \pm 1.7$ & $4.9 \pm 2.0$ \\
\hline 25th percentile $(\mathrm{cm})$ & & 4 & 3 & 3 \\
\hline Median (cm) & & 5 & 4 & 4 \\
\hline 75th percentile $(\mathrm{cm})$ & & 6 & 5 & 6 \\
\hline $\operatorname{Min}-\operatorname{Max}(\mathrm{cm})$ & & $2-20$ & $1-15$ & $1-20$ \\
\hline$\% \geq 6 \mathrm{~cm}$ & & 36.9 & 20.2 & 28.8 \\
\hline$\% \geq 8 \mathrm{~cm}$ & & 12.3 & 5.6 & 9.0 \\
\hline Thick-textured uterine wall & 1799 & 77.7 & 77.8 & 77.7 \\
\hline Palpable uterine lumen & 1790 & 40.7 & 34.2 & 37.5 \\
\hline Dominant palpable ovarian structure & 1816 & & & \\
\hline No structures & & 30.4 & 22.5 & 26.5 \\
\hline Corpus luteum & & 41.3 & 43.4 & 42.4 \\
\hline Follicle & & 24.4 & 28.2 & 26.3 \\
\hline Cyst & & 3.9 & 6.0 & 4.9 \\
\hline
\end{tabular}

ever, the category of clear mucus with flecks of pus was not associated $(P=0.26)$ with reduced pregnancy rate. When this category was dropped from the model and became part of the referent group, mucopurulent discharge tended $(P=0.09)$ to increase time to pregnancy. Purulent or foul discharge was consistently associated with a $20 \%$ reduction in pregnancy rate. Whether modeled in all cows with the effect of treatment controlled by forced inclusion in the model, or in only those cows that never received treatment, the final variables that defined endometritis and their parameter estimates were the same.

The effects of discharge and cervical diameter $>7.5$ $\mathrm{cm}$ on pregnancy rate depended on the interval postpartum at which these findings were made $(P$ values for terms for the interaction of mucopurulent, purulent, or foul discharge by week, and cervix $>7.5 \mathrm{~cm}$ by week were 0.06 and 0.07 , respectively). Specifically, mucopurulent discharge only significantly affected pregnancy rate if found after 27 DIM. Cervical diameter $>7.5 \mathrm{~cm}$ was significantly associated with reduced pregnancy rate throughout the study period, but its effect was greater between 27 and 33 DIM. Therefore, the models were stratified by week of the enrollment period. Between 20 and 26 DIM inclusive, mucopurulent discharge was not associated with subsequent pregnancy rate. Therefore, in the stratified model, this category was dropped, leaving only purulent or foul discharge, relative to all other categories of discharge, in the model (Table 3). Cows with purulent or foul discharge in wk 1 of the study period had a HR for pregnancy of 0.83 (95\% confidence interval 0.65 to $1.07, P=0.16$ ), or a $17 \%$ reduction in pregnancy rate. Despite the relatively large $P$ value, this category was retained as part of the case definition of endometritis. In the overall analysis (Table 2 ), undifferentiated pus discharge was significantly as- 
Table 2. Defining clinical endometritis: initial proportional hazards regression models of clinical findings that are associated with time to pregnancy (relative pregnancy rate) in 1865 Holstein cows undergoing routine reproductive examination, including inspection of the perineum, vaginoscopy, and transrectal palpation between 20 and 33 DIM.

\begin{tabular}{|c|c|c|c|c|c|c|}
\hline \multirow[b]{2}{*}{ Finding } & \multicolumn{2}{|c|}{ Overall } & \multicolumn{2}{|c|}{ Examined at 20 to $26 \mathrm{DIM}$} & \multicolumn{2}{|c|}{ Examined at 27 to $33 \mathrm{DIM}$} \\
\hline & $\begin{array}{l}\mathrm{HR}^{1} \\
\text { pregnancy }\end{array}$ & $P$ & $\begin{array}{l}\text { HR } \\
\text { pregnancy }\end{array}$ & $P$ & $\begin{array}{l}\text { HR } \\
\text { pregnancy }\end{array}$ & $P$ \\
\hline Any visible pus ${ }^{2}$ & 0.81 & 0.001 & 0.80 & 0.002 & 0.79 & 0.02 \\
\hline Cervix $>7.5 \mathrm{~cm}$ & 0.79 & 0.007 & 0.85 & 0.12 & 0.59 & 0.01 \\
\hline Palpable $\mathrm{CL}^{3}$ & 1.20 & 0.02 & 1.21 & 0.07 & 1.23 & 0.04 \\
\hline Palpable follicle ${ }^{3}$ & 1.23 & 0.03 & 1.20 & 0.12 & 1.28 & 0.03 \\
\hline
\end{tabular}

${ }^{1}$ Hazard ratio (instantaneous relative risk) of pregnancy for cows with endometritis relative to cows without endometritis, adjusted for parity group, treatment and intra-herd correlation.

${ }^{2}$ Found on inspection of the perineum or by vaginoscopy.

${ }^{3}$ Relative to no palpable structures.

sociated with reduced pregnancy rate $(\mathrm{HR}=0.80)$, both between 20 and 26 DIM and between 27 and 33 DIM. The fact that the refined classification of discharge maintained approximately the same magnitude of effect, but had a much larger $P$ value, is attributable to the greatly reduced number of animals (362 cows with any purulent discharge versus 98 with purulent or foul discharge between 20 and 26 DIM), and corresponding loss of statistical power.

Combining the results of all models of criteria for diagnosis of endometritis, based on impact on pregnancy rate (Table 3), clinical endometritis was defined as the presence of purulent or foul discharge, or cervical diameter $>7.5 \mathrm{~cm}$ between 20 and 33 DIM, or mucopurulent discharge after 26 DIM, when cows are examined between 20 and 33 DIM, and vaginoscopy is performed.

Of 1865 cows examined, 316 cows (16.9\%) were classified as having clinical endometritis based on the case definition derived here. Of these, 193 cases were diagnosed on the basis of discharge (61.1\%), including 55 cases (17.4\% of the total) diagnosed on inspection and 138 cases ( $43.7 \%$ of the total) diagnosed by vaginoscopy. A further 91 cases $(28.8 \%$ of the total) were identified based on cervical diameter in the absence of discharge, and 32 cows ( $10.1 \%$ of cases) had both discharge and a large cervix. The prevalence of clinical endometritis varied between herds from 5 to $26 \%$. The prevalence of clinical endometritis across the postpartum interval studied is shown in Figure 1.

The presence of a large cervix and purulent uterine discharge, as defined here, were better predictors of pregnancy than any assessment of the uterus by palpation. However, if vaginoscopy was not performed and diagnosis of endometritis was based on history, inspection and palpation, three findings were associated $(P<$ $0.05)$ with reduced pregnancy rate. These included the

Table 3. Final proportional hazards regression models of time to pregnancy to derive a case definition of clinical endometritis in 1865 Holstein cows undergoing routine reproductive examination, including inspection of the perineum, vaginoscopy, and transrectal palpation between 20 and 33 DIM.

\begin{tabular}{|c|c|c|c|c|c|c|c|c|}
\hline \multirow[b]{2}{*}{ Variable } & \multicolumn{4}{|c|}{$\begin{array}{l}\text { Examined } 20 \text { to } 26 \text { DIM } \\
\mathrm{n}=916\end{array}$} & \multicolumn{4}{|c|}{$\begin{array}{l}\text { Examined } 27 \text { to } 33 \text { DIM } \\
\mathrm{n}=880\end{array}$} \\
\hline & $\beta$ & $\begin{array}{l}\text { Robust } \\
\mathrm{SE}^{1}\end{array}$ & $\mathrm{HR}^{2}$ & $P$ & $\beta$ & $\begin{array}{l}\text { Robust } \\
\text { SE }\end{array}$ & HR & $P$ \\
\hline \multicolumn{9}{|l|}{ Discharge } \\
\hline Mucopurulent & $\ldots$ & & & & -0.34 & 0.16 & $0.71^{4}$ & 0.03 \\
\hline Purulent or foul & -0.18 & 0.13 & $0.83^{3}$ & 0.16 & -0.29 & 0.12 & $0.75^{4}$ & 0.02 \\
\hline Cervix $>7.5 \mathrm{~cm}$ & -0.24 & 0.10 & 0.79 & 0.02 & -0.52 & 0.20 & 0.59 & 0.01 \\
\hline \multicolumn{9}{|l|}{ Ovary $^{5}$} \\
\hline CL & 0.21 & 0.11 & 1.24 & 0.05 & 0.19 & 0.10 & 1.21 & 0.06 \\
\hline Follicle & 0.18 & 0.12 & 1.20 & 0.13 & 0.24 & 0.11 & 1.27 & 0.03 \\
\hline
\end{tabular}

${ }^{1}$ Robust standard error from the proportional hazard leverage macro in SAS.

${ }^{2}$ Hazard ratio (instantaneous relative risk) of pregnancy adjusted for effects of herd, parity group, treatment, and presence of CL or follicle.

${ }^{3}$ Relative to cows with no discharge, clear mucus, mucus with flecks of pus, or mucopurulent discharge; $95 \%$ confidence interval $(0.65-1.07)$.

${ }^{4}$ Relative to cows with no discharge, clear mucus, or mucus with flecks of pus.

${ }^{5}$ Relative to no palpable structures. 


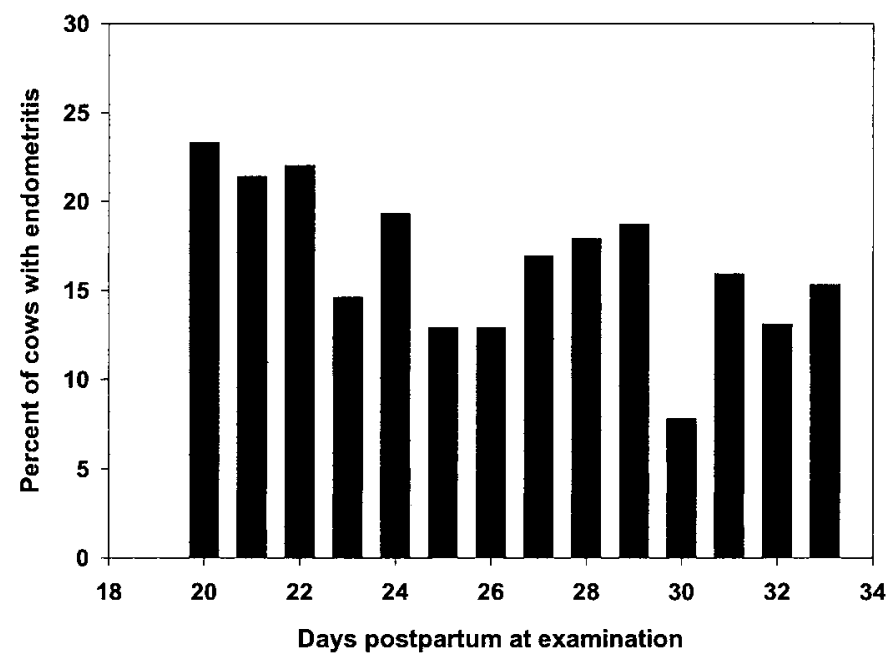

Figure 1. The apparent prevalence of clinical endometritis in 1865 Holstein cows undergoing routine reproductive examination, including inspection of the perineum, vaginoscopy, and transrectal palpation between 20 and 33 DIM. Endometritis was defined as the presence of purulent or foul uterine discharge or cervical diameter $>7.5 \mathrm{~cm}$ throughout the examination period, or the presence of mucopurulent discharge after 26 DIM.

presence of mucopurulent or purulent discharge on the perineum, cervical diameter $>7.5 \mathrm{~cm}$, and presence of a uterine horn $\geq 8 \mathrm{~cm}$ in diameter. Using these criteria, the apparent prevalence of endometritis was $14.6 \%$. As in the full model, there was an interaction of cervical diameter with week of the study period, but the effect of uterine size did not depend on time. Overall, there was a high level of agreement between the case definition derived in the full model (Table 3), and the surrogate diagnostic criteria when vaginoscopy was ignored (Kappa $=0.60$, McNemar's $P=0.009$ ). Cows with endometritis were more likely to have no palpable ovarian structures at examination than unaffected cows ( 35 and $25 \%$ of cows, respectively, $P=0.0003$ ).
Mature cows (in their third or greater lactation) were at greater risk of clinical endometritis than were cows in their second or first lactation (prevalences of 21, 13, and $12 \%$, respectively, $P<0.001$ ). There was no effect of season of calving on risk of endometritis. Each of twins [odds ratio $(\mathbf{O R})=8.6, P<0.001$ ], retained placenta $(\mathrm{OR}=4.9, P<0.001)$, and metritis $(\mathrm{OR}=4.6, P$ $<0.001$ ) was independently associated with increased risk of endometritis. Veterinary-assisted calving had no significant effect on the probability of clinical endometritis.

\section{Impact of Clinical Endometritis on Reproductive Performance}

Simple associations of clinical endometritis with measures of reproductive performance are reported in Table 4 and Figure 2. Because these associations do not consider possible confounders, the tests of significance should only be considered a general measure of association. Given the clear crude association of endometritis with reproductive performance, multivariable models accounting for correlation of cows within herd and the effects of covariates were built for each reproductive outcome and are summarized in Table 5. By definition, cows with endometritis had a reduced pregnancy rate. On average, the magnitude of this reduction was $27 \%$ in relative pregnancy rate (e.g., a decrease in 21-d pregnancy rate from 20 to $14.6 \%$ ). However, the effects of discharge and large cervical diameter were more severe in the latter half of the study period $(\mathrm{HR}=0.71$ and 0.59 , respectively). Parameter estimates ( $\beta$ 's) are additive on the logarithmic scale. Therefore, the results in Table 3 indicate that cows that had both purulent discharge and a large cervix were more severely affected than cows with only one sign of endometritis. Conversely, the presence of a CL or follicle at the time of diagnosis counteracted the impact of endometritis. Between 20

Table 4. Crude associations of clinical endometritis with absolute measures of reproductive performance in 1865 Holstein cows undergoing routine reproductive examination, including inspection of the perineum, vaginoscopy, and transrectal palpation between 20 and 33 DIM.

\begin{tabular}{lccc}
\hline & \multicolumn{2}{c}{ Endometritis } & \\
\cline { 2 - 3 } Variable & Yes & No & $P$ \\
\hline Median days to first breeding1 & 80 & 75 & 0.0002 \\
Pregnant to first insemination (\%) & 29.8 & 37.9 & 0.01 \\
Cumulative pregnancy risk (\%) & 70.6 & 79.6 & 0.0004 \\
Pregnant by 120 DIM (\%) & 33.5 & 47.4 & 0.0001 \\
Median days open & 150 & 122 & 0.0001 \\
Number of AI (pregnant cows) & 2.35 & 2.15 & 0.06 \\
Culled for any reason (\%) & 27.9 & 21.1 & 0.01 \\
Culled for reproductive failure (\%) & 6.7 & 3.8 & 0.02 \\
\hline
\end{tabular}

${ }^{1}$ Survival analysis-accounts for cows that were inseminated and those that were not.

${ }^{2}$ Survival analysis-accounts for cows that became pregnant and those that did not. 


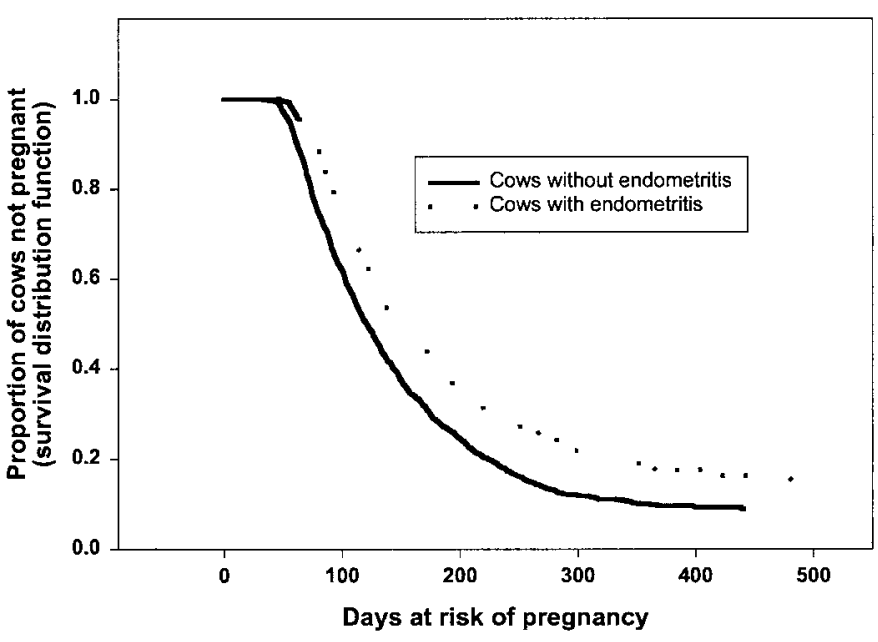

Figure 2. Survival function curves for time to pregnancy (days open) for 1865 Holstein cows with and without clinical endometritis diagnosed between 20 and 33 DIM. Endometritis was defined as the presence of purulent or foul uterine discharge or cervical diameter $>7.5 \mathrm{~cm}$ throughout the examination period, or the presence of mucopurulent discharge after 26 DIM.

and 26 DIM, the presence of a CL effectively negated the effect of either purulent discharge or cervical diameter $>7.5 \mathrm{~cm}$, but not both.

Adjusted for covariates, median time to pregnancy was $32 \mathrm{~d}$ longer in cows with clinical endometritis than in normal cows (Table 5). This result was driven in part by a slight delay in first insemination $(3 \mathrm{~d})$ and a substantial reduction in first service pregnancy risk (OR $=0.69, P=0.05)$. Cows with endometritis that became pregnant required $10 \%$ more inseminations than cows without endometritis. As a result of these impairments in reproductive performance, cows with clinical endometritis were 1.7 times more likely to be culled for reproductive failure than unaffected cows.

The characteristics of the diagnostic test for clinical endometritis were calculated using nonpregnancy beyond 120 or 150 DIM as gold standards for the presence of a significant reproductive problem. For the definition of endometritis derived here, the sensitivity was $20 \%$, and the specificity was $88 \%$ for both cut-points. The sensitivity and specificity were identical whether they included all cows or only those cows that were inseminated at least once. For the palpation-based case definition, ignoring vaginoscopy, the sensitivity and specificity were 17 and $88 \%$, respectively, for nonpregnancy beyond either 120 or 150 DIM. The impact of these diagnostic criteria on reproductive performance was substantial (HR for pregnancy $=0.72$, and an increase of $34 \mathrm{~d}$ in median time to pregnancy). However, between 27 and 33 DIM, diagnosis of endometritis including vaginoscopy was more sensitive than palpation-based diagnosis (21 vs. $12 \%$ sensitivity for classification of nonpregnancy beyond 150 DIM, respectively). During this period, the specificity of the two diagnostic approaches was comparable (89 and $94 \%$, respectively). Between 27 and 33 DIM, 24\% of cases of endometritis were identified by external inspection, $64 \%$ required

Table 5. Summary of multivariable survival analysis and logistic regression models of the impact of clinical endometritis on reproductive performance in Holstein cows undergoing routine reproductive examination, including inspection of the perineum, vaginoscopy, and transrectal palpation between 20 and 33 DIM.

\begin{tabular}{|c|c|c|c|c|}
\hline \multirow[b]{2}{*}{ Variable } & \multirow[b]{2}{*}{$\mathrm{n}$} & \multicolumn{2}{|c|}{$\begin{array}{l}\text { Cows with endometritis, } \\
\text { relative to cows without }\end{array}$} & \multirow[b]{2}{*}{$P$} \\
\hline & & Estimate $^{2}$ & $95 \% \mathrm{CI}$ & \\
\hline \multicolumn{5}{|l|}{ Relative measures } \\
\hline Days to first breeding ${ }^{3}$ & 1811 & $\mathrm{HR}=0.86$ & $0.73-1.01$ & 0.05 \\
\hline First service pregnancy risk ${ }^{4}$ & 1600 & $\mathrm{OR}=0.69$ & $0.49-0.99$ & 0.05 \\
\hline Relative pregnancy rate (time to pregnancy $)^{5}$ & 1811 & $\mathrm{HR}=0.73$ & $0.64-0.84$ & 0.0001 \\
\hline Number of AI (pregnant cows) ${ }^{6}$ & 1492 & $\mathrm{RR}=1.09$ & $0.98-1.20$ & 0.10 \\
\hline Culled for reproductive failure & 1811 & $\mathrm{OR}=1.73$ & $1.12-2.69$ & 0.02 \\
\hline Actual time to event & & Yes & No & \\
\hline Median days to first breeding & 1811 & 78 & 75 & 0.03 \\
\hline Median days to pregnancy & 1811 & 151 & 119 & 0.0001 \\
\hline
\end{tabular}

${ }^{1}$ Adjusted for parity, treatment, presence of a palpable CL or follicle, and correlation of cows within herd.

${ }^{2} \mathrm{HR}=$ hazard ratio; $\mathrm{OR}=$ odds ratio; $\mathrm{RR}=$ relative risk.

${ }^{3}$ Survival analysis-includes cows that were inseminated and those that were not. Also adjusted for the effect of metritis $(\mathrm{RR}=0.60, P=0.02)$.

${ }^{4} \mathrm{Also}$ adjusted for the effect of twins (OR $\left.=0.26, P=0.04\right)$.

${ }^{5}$ Survival analysis-includes cows that became pregnant and those that did not.

${ }^{6}$ For number of inseminations, $\mathrm{RR}$ is interpreted as the relative difference in the number of inseminations, i.e., 1.09 means that cows with endometritis had $9 \%$ more inseminations than cows without endometritis. Only adjusted for parity group and the random effect of herd. 
vaginoscopy, and only $12 \%$ were diagnosed on the basis of cervical diameter in the absence of significant discharge.

\section{DISCUSSION}

This study of endometritis in dairy cattle is one of the largest to date and is one of few that associate clinical findings in the postpartum period with reproductive performance. It is the first to employ multivariable survival analysis to measure time to pregnancy, thereby accounting for cows that fail to become pregnant and for significant covariates. The first objective was to identify risk factors or clinical findings that were significantly associated with reduced pregnancy rate, in the absence of systemic signs. Therefore, clinical endometritis was defined in terms of measured impact on actual reproductive performance, and not in pathological or clinical terms relative to perceived normal involution.

Because uterine conditions were expected to be dynamic during the examination period, the analyses were stratified into earlier (20 to $26 \mathrm{DIM}$, inclusive) and later (27 to 33 DIM, inclusive) intervals postpartum. Although these strata might be criticized as arbitrary, they were selected before analysis. On average, dairy cows are expected to have their first postpartum ovulation between 14 and 28 DIM (Morrow et al., 1966; Leslie, 1983; Stevenson and Call, 1988). Therefore, many cows were expected to reinitiate cyclicity and acquire a $\mathrm{PGF}_{2 \alpha}$-responsive corpus luteum during the examination period, which would influence measures of involution (Morrow et al., 1966).

Given all available information from postpartum history, inspection, vaginoscopy, and palpation, only the presence of purulent discharge and cervical diameter were significantly associated with increased time to pregnancy. The presence of mildly purulent uterine discharge (i.e., mucus with flecks of pus) until 33 DIM was not associated with reduced pregnancy rate. However, increasingly purulent discharge was associated a greater impact on pregnancy. Because involution was ongoing during the examination period, it is not surprising that the effect of the significant clinical findings on reproductive performance depended on when they were found. The presence of mucopurulent or purulent discharge that persisted into the fourth week postpartum had greater relevance for reproductive performance. Likewise, although cervical diameter $>7.5 \mathrm{~cm}$ was associated with increased time to pregnancy throughout the examination period, its effect was worsened significantly if it persisted beyond 26 DIM.

With each refinement of the case definition based on category of discharge and with stratification by week of the study period, the number of cows within each stratum with significant pathology was reduced; consequently, statistical power was reduced. The case definition of clinical endometritis between 27 and 33 DIM, as derived here, was clear and statistically significant. Between 20 and 26 DIM cows with purulent or foul discharge had a $17 \%$ reduction in pregnancy rate relative to cows with no discharge or clear mucus (Table 3 ). This is biologically and economically important, despite its lack of statistical significance $(P=0.16)$. Rothman and Greenland (1998) make the case that adherence to arbitrary statistical hypothesis testing without consideration of estimation of effect may lead to type II errors (false negative) with respect to the biological hypothesis under consideration. In this case, the $95 \%$ confidence interval around the HR was 0.65 to 1.07 , strongly suggesting a negative effect. Because there was an effect of undifferentiated discharge in this time period, it was not sensible that refinement of the classification should cause this effect to disappear. Rather, the fact that the HR was essentially the same, but the $P$ value much larger suggests a biologic effect, but a lack of statistical power. Therefore, the category of purulent discharge between 20 and 26 DIM was retained as part of the case definition of endometritis. The importance of the exact case definition between 20 and 26 DIM should not be overemphasized. First, relative to endometritis diagnosed between 27 and 33 DIM, the same clinical findings earlier had less impact on time to pregnancy (Table 3). Moreover, subsequent analyses of the effect of treatment (LeBlanc et al., 2002) showed that there was no benefit of treatment between 20 and 26 DIM. Therefore, the level of significance of purulent discharge at this time is important in principle, but has little application in clinical practice.

These results underscore the importance of considering the normal process of uterine involution when examining postpartum cows. For example, although it may seem counter-intuitive, the presence of mucopurulent discharge before $27 \mathrm{DIM}$, and the presence of mucus with flecks of pus anytime during the study period had no association with eventual reproductive performance. Other studies that have considered uterine discharge have generally not distinguished among different categories of discharge and have simply assumed that any pus-like discharge is abnormal (Miller et al., 1980; Oltenacu et al., 1983; Thurmond et al., 1993). The presence of mildly purulent uterine discharge in the first month postpartum likely reflects a successful immune response by the cow to a bacterial challenge.

Plausibly, finding purulent discharge externally as opposed to requiring vaginoscopy for identification might imply that there was a greater volume of discharge. Conversely, the likelihood of finding discharge 
externally may be confounded by the occurrence of estrus around the time of examination. Increased production of vaginal and cervical mucus, as well as increased myometrial contractions around estrus would increase the probability of discharge being moved externally, but would also plausibly favor resolution of endometritis (Gilbert, 1997).

It is biologically sensible that the presence of purulent uterine discharge should be a good summary indicator for assessment of postpartum uterine health. The presence of pus discharge on vaginoscopy is highly correlated with active bacterial infection of the uterus (Miller et al., 1980; Dohmen et al., 1995). Whether or not active infection is a necessary cause of endometritis, the evidence suggests that prior or ongoing chronic infection with pathogenic bacteria is a component cause of uterine inflammation (Semambo et al., 1991; Bondurant, 1999). Most postpartum risk factors (twins, retained placenta, metritis, or other antecedent peripartum disease) make chronic infection of the uterus with pathogens more likely. Interestingly, despite being independently associated with clinical endometritis, none of those variables (twins, retained placenta, or metritis) remained in the models as factors associated with pregnancy rate, even when discharge was ignored. This underscores the result that given specific, valid information later in the postpartum period, these prior events are risk factors, not diagnostic criteria for impaired fertility. For diagnosis of clinical endometritis, the question is whether or not abnormalities that are significantly associated with reduced pregnancy rate are in fact present, or alternatively, whether the cow has successfully resolved postpartum uterine contamination. Palpation of the uterus is an attempt to identify cows that have impediments to timely pregnancy, but the present results do not support this approach, given that vaginoscopy is performed.

Delayed involution of the cervix (cervical diameter $>7.5 \mathrm{~cm}$ ) was the only other independent predictor of reduced pregnancy rate. The cervix normally involutes at a slower rate than the uterus, but both organs are expected to reach a diameter of $<5 \mathrm{~cm}$ by 25 DIM in normal cows (Morrow et al., 1966). It is biologically sensible that an enlarged cervix should predict reduced pregnancy rate independent of uterine findings, because there is likely less variability in the size of the fully involuted cervix than in the location or size of the uterus after involution. There is another large study that focused on the association of postpartum uterine discharge and cervical size with reproductive performance (Oltenacu et al., 1983). In that study, cows with a large cervix had a significantly decreased risk of pregnancy at first insemination and significantly increased mean days open. They concluded that the optimum time to assess cervical involution was $3 \mathrm{wk}$ postpartum, and that the optimum threshold was $6 \mathrm{~cm}$. Considered with the present data, it appears that cervical diameter of $<5$ $\mathrm{cm}$ is clearly not associated with impaired reproduction, but that the critical threshold lies between 6 and $7.5 \mathrm{~cm}$.

Cows with clinical endometritis were more likely than unaffected cows to have no palpable ovarian structures. This is in agreement with other reports that cows with slow involution (Madej et al., 1984), dystocia, twins, or retained placenta (Morrow et al., 1966; Fonseca et al., 1983) take 9 to $19 \mathrm{~d}$ longer (until 29 to 34 DIM) until first ovulation than normal cows.

It is important to emphasize that almost half (44\%) of cases were identified by vaginoscopy alone, and that the case definition and results depend on its inclusion in the diagnostic process. Given inspection and vaginoscopy, no uterine palpation findings were significantly associated with pregnancy rate. This has major practical clinical significance because the most common diagnostic technique for endometritis in clinical practice is rectal palpation, whereas vaginoscopy is an uncommonly employed diagnostic tool (Youngquist and Shore, 1997). Before the present study, there has been little information to confirm or refute the predictive value of postpartum inspection, vaginoscopy, or palpation for reproductive performance. Notwithstanding its simplicity and rapidity, there will likely be resistance to adoption of vaginoscopy because of perceived inconvenience to practitioners. This may be overcome in part by reassurance that the brief vaginoscopic examination need only be a clean procedure, preceded by a simple wiping of the vulva with paper towels (as is done for artificial insemination). Because vaginoscopy is not widely employed and may be perceived to be inconvenient to clinicians, a set of surrogate diagnostic criteria, not employing vaginoscopy, was also derived. The palpation-based diagnostic criteria agreed well overall with the primary case definition because there was considerable overlap in the two case definitions. Both included the presence of mucopurulent or purulent discharge externally, and cervical diameter $>7.5 \mathrm{~cm}$. In the absence of vaginoscopy, cows with a uterine horn $\geq 8 \mathrm{~cm}$ in diameter had a reduction in pregnancy rate similar to cows with vaginoscopically diagnosed discharge ( $\mathrm{HR}=0.83$ and 0.80 to 0.86 , respectively). However, between 27 and 33 DIM, diagnosis of endometritis, including vaginoscopy, is more sensitive and comparably specific compared with palpation-based diagnosis, underlining the importance of vaginoscopy over palpation in this timeframe. Vaginoscopy may be a more objective and precise diagnostic test than transrectal manual measurement of the uterus. Moreover, as purely technical tasks on larger dairies are increasingly delegated to workers with only basic training, vaginos- 
copy can be performed quickly with minimal skill but likely with high repeatability.

The examination period used in this study overlapped with the interval for normal postpartum involution. Therefore, a more epidemiologically specific case definition was warranted to avoid over-diagnosis and, by extension, practically and economically unnecessary treatment of endometritis. However, this window of time corresponds to the period when postpartum examinations are commonly performed (Miller et al., 1980; Bonnett et al., 1993).

Fifteen clinicians participated in examination of cows in this study, which leaves open the possibility of imprecision in the classification of uterine discharge and palpation findings. The data did not allow for calculation of inter-rater or intra-rater agreement on clinical measurements, or for assessment of the accuracy of palpation findings. There is evidence of considerable interclinician variability in the accuracy of assessment of CL function by palpation (Kelton et al., 1991). However, data to evaluate the precision of measurement of the uterus by rectal palpation are lacking. It is likely that classification of discharge by vaginoscopy is more repeatable over time and between examiners than measurement of the uterine horns by palpation. Unfortunately, the present data do not allow this hypothesis to be tested. It is possible that clinicians' assessment of the cervix or uterus by palpation may have been biased by prior knowledge of the presence and nature of uterine discharge. We decided to perform inspection and vaginoscopy before palpation on the basis that vaginoscopy might be a useful diagnostic test in the absence of palpation. This may have resulted in some falsenegative findings with respect to discharge.

In the present study, $30.1 \%$ of cows had some pus discharge, but only $16.9 \%$ had discharge or palpation findings that were associated with reduced pregnancy rate. Notably, approximately $13 \%$ of the cows examined had uterine discharge that traditionally was considered abnormal, but had no association with subsequent pregnancy rate. It is difficult to compare the prevalence of endometritis with others in the literature because so few reports include a detailed case definition, few employed vaginoscopy, and fewer still relate findings to pregnancy rate. Among cows that were routinely examined by palpation between 20 and 40 DIM, the apparent prevalence of endometritis varied from 3.7 to $18.0 \%$, with an unweighted mean of 9.7\% (Sandals et al., 1979; Erb et al., 1980; Dohoo et al., 1983; Erb et al., 1984; Curtis et al., 1985; Erb et al., 1985; Etherington et al., 1985; Bartlett et al., 1986; Correa et al., 1993). In one study in which vaginoscopy was used to diagnose endometritis between 21 and 35 DIM, the apparent prevalence was 26\% (Miller et al., 1980), which is close to the prevalence of any pus discharge reported here. In another large field study in which cows were examined vaginoscopically between 22 and 28 DIM, the prevalence of purulent discharge of any character was 34\%, (Heuwieser et al., 2000). Inclusion of vaginoscopy in a postpartum examination may increase the apparent prevalence of endometritis, but only if the results are interpreted without reference to their impact on pregnancy rate.

When measured against reproductive performance, any diagnostic test for endometritis will have less than $100 \%$ sensitivity because there are several independent reasons for which cows fail to become pregnant in a timely way, or at all. Although the case definition of clinical endometritis derived here is based on impact on pregnancy rate, it can be expected to produce some false negative results. In some cases, this corresponds to cows that have meaningful endometrial pathology, but do not produce visible purulent discharge, or whose discharge is not observed at examination, and that do not have a large cervix. There are no data available that describe the shedding pattern of uterine discharge in cows with endometritis, although it seems likely that as long as purulent liquid is present, it will be discharged more or less constantly as the uterus shrinks with the cervix still slightly open. However, in many cows, infertility is unrelated to uterine disease, but may be associated with poor estrus detection or insemination technique, heat stress, inadequate body condition, or suboptimal nutritional status.

By defining endometritis with the threshold discharge score, on average, cows with mucopurulent or worse discharge have a significantly reduced pregnancy rate. Therefore, the false-positive rate is likely very low, yet impossible to quantify from available data. Calculation of the sensitivity, specificity, and predictive value of a diagnostic test requires dichotomization of both test results and the gold standard outcome. With respect to reproductive performance, the outcome might reasonably be dichotomized into pregnancy by 120 DIM, accepting that this approach is arbitrary. Employing the present definition of endometritis to a threshold of pregnancy by 120 DIM, the test has a sensitivity of $20 \%$ and specificity of $88 \%$. These test characteristics are not as strong as those found by Bonnett et al. (1993) who achieved $92 \%$ sensitivity and $77 \%$ specificity for pregnancy by 120 DIM using a combination of three uterine biopsy findings with follicular status. However, their methodology was considerably more invasive, complex, and time-consuming. Additionally, their study was conducted in a single herd with a high incidence of dystocia and metritis, where uterine disease likely explained more of the variability in reproductive performance than would be expected in a broader sample 
of herds. For clinical application of a diagnostic test, predictive values are more useful than sensitivity and specificity, but the former depend on the true prevalence of disease. Although the present study identifies clinical signs that classify postpartum cows with a prolonged interval to pregnancy, the true prevalence of endometritis is unknown. The fraction of infertility attributable to endometritis is similarly unknown, and likely varies among herds.

Rectal palpation is documented to be a substantially imperfect test of ovarian status and luteal function (Kelton et al., 1991). Notwithstanding, palpation-based evidence of cyclicity (presence of either a palpable CL or follicle as the dominant ovarian structure) during the study period was associated with approximately a $20 \%$ increase in pregnancy rate, relative to cows with no palpable structures. This is in agreement with Bonnett et al. (1993), who found that presence of a follicle at 26 DIM was associated with a $10 \%$ increase in the odds of pregnancy by 120 DIM, adjusted for histologic evidence of endometritis.

\section{Impact of Clinical Endometritis on Reproductive Performance}

The general goal for postpartum reproductive health in dairy cattle is for the uterus to be completely involuted and free of infection, and for cows to be cyclic by the time they enter the breeding period (after 50 to 60 DIM). If clinical endometritis is to be diagnosed in terms of findings that are associated with a meaningful impairment in fertility, the outcome measures must also be defined judiciously. The key outcomes in reproductive performance are the occurrence of pregnancy and the time from calving until pregnancy; the number of inseminations required is also of some importance (Ferguson and Galligan, 2000). Ultimately, the economic imperative is to maximize the proportion of cows that become pregnant between 85 and 120 DIM (Dijkhuizen et al., 1985; Plazier et al., 1997).

By definition, endometritis is a localized condition of the uterus. Therefore, there are no death losses attributable to endometritis. Similarly, no milk production loss is expected with endometritis, and this has been confirmed by a recent meta-analysis (Fourichon et al., 1999). Because there are no systemic signs, it is difficult to quantify whether endometritis causes discomfort to cows or otherwise directly reduces their welfare. Accordingly, the measurable effects of endometritis are mediated entirely through impacts on reproductive performance. These are manifest as direct costs for treatment, labor, examinations, insemination, hormones for reproductive management, and heat detection aids, and opportunity costs of having cows spend less of their lifetime in more profitable early lactation, and culling of otherwise meritorious cows because of nonpregnancy.

Also by definition, cows with endometritis had a longer time to pregnancy. Contributing to this, affected cows had a $30 \%$ relative reduction in the probability of pregnancy at first insemination. Cows with clinical endometritis were also less likely to become pregnant at all, and correspondingly $70 \%$ more likely to be culled for reproductive failure. It took approximately $32 \mathrm{~d}$ longer for half the cows with endometritis to become pregnant than it did for unaffected cows, adjusted for herd, parity, ovarian structures, and treatment. In a large field study in two herds that employed both vaginoscopic diagnosis of endometritis and survival analysis (Thurmond et al., 1993), endometritis increased median days open by 6 to $11 \mathrm{~d}$. However, the reported between-herd difference may be confounded by the fact that in the first herd cows were examined on average at 21 DIM, but in the second herd at 13 DIM. In both cases, this was earlier than in the present study, therefore a lesser impact on time to pregnancy may be expected. As demonstrated in the present study, the earlier examination is performed, the greater is the overlap of uterine discharge between nonsignificant and that which is predictive of reduced pregnancy rate. Furthermore, Thurmond et al. (1993) diagnosed endometritis as any purulent discharge, which would include many cows without a significant reduction in pregnancy rate. In a study by survival analysis, but without explicit diagnostic criteria reported, cows with endometritis had a hazard ratio for pregnancy of 0.83 , which increased the median time to pregnancy from 110 to 125 d (Lee et al., 1989).

Because the measurement of time to pregnancy reported here is based on a comparison of median days open and included censored cows, it is not directly comparable to published estimates of differences in mean days open. Nevertheless, the latter vary from 0 to 48 additional days open for cows with endometritis, with an unweighted mean of $16 \mathrm{~d}$ (Sandals et al., 1979; Miller et al., 1980; Dohoo et al., 1983; Etherington et al., 1985; Bartlett et al., 1986; Oltenacu et al., 1990; Tenhagen and Heuwieser, 1999). In a recent meta-analysis of the effect of disease on reproductive performance (Fourichon et al., 2000), the hazard ratio for pregnancy was 0.84 for cows with endometritis, which is less severe than in the present study. However, the studies summarized used traditional approaches to diagnosis of endometritis. The meta-analysis also calculated increases of 15.3 and 27.7 mean days open in cows with endometritis that became pregnant, and all cows with endometritis, respectively, relative to unaffected cows. The latter figure is partially comparable to the estimated additional time to pregnancy calculated by survival 
analysis, in that both account for cows that failed to become pregnant. Again, the present diagnostic criteria identify cows with more severe impairment than the averages in the literature. Interestingly, the estimates of the impact of endometritis in the meta-analysis were not affected by the average reproductive performance in the constituent studies.

Cows with endometritis were $73 \%$ more likely to be culled for reproductive failure, which lends credence to the diagnostic criteria proposed here. In other reports, the impact of endometritis on culling is equivocal, with relative risks of zero to 1.4 (Erb et al., 1985; Bartlett et al., 1986; Grohn et al., 1998; Oltenacu et al., 1990). However, these all measured crude risk of culling, whereas the present study isolated those cows for which nonpregnancy is most likely the true cause of removal from the herd.

\section{CONCLUSIONS}

If a cow-level approach to postpartum endometritis is taken, examination should start after approximately $28 \mathrm{DIM}$ and should include vaginoscopy. Clinical endometritis can be diagnosed by the presence of purulent or foul uterine discharge or cervical diameter $>7.5 \mathrm{~cm}$ after 20 DIM, or mucopurulent discharge after 26 DIM. Two simple and objective clinical findings (the presence of mucopurulent or purulent discharge from the cervix, or cervical diameter $>7.5 \mathrm{~cm}$ ) identified cows at risk of a significantly prolonged time to pregnancy with high specificity. Given external inspection, vaginoscopic examination, and palpation of the cervix between 20 and 33 DIM, all other prior reproductive abnormalities and uterine palpation findings are not significantly predictive of time to pregnancy. Practitioners who continue to diagnose and treat endometritis on the basis of uterine palpation alone, or on the basis of criteria other than horn diameter, must be aware that they will make a considerable number of false-positive diagnoses and administer treatments that may have no economic benefit to the client. In the absence of vaginoscopy, external inspection and rectal palpation to assess whether the diameter of the cervix or the horns of the uterus exceed $8 \mathrm{~cm}$ will approximate a diagnosis that includes vaginoscopy. Ovarian evidence of cyclicity by 20 DIM is a favorable sign for time to pregnancy. Accounting for other factors, cows with endometritis between 20 and 33 DIM take $27 \%$ longer (relative difference in pregnancy rate, not absolute units of difference) to become pregnant than cows without endometritis.

The present results raise the question of whether the effort involved with individual cow examination for endometritis is economically justifiable at the herd level. The diagnostic criteria developed in the present study are simple, objective, and specifically identified cows with a substantial reduction in pregnancy rate, which is economically important in the affected individuals. Whether the effort to find these cows is profitable for the dairy will depend on the baseline reproductive performance in the herd, the prevalence of endometritis, the efficacy of treatment, and the cost of performing the examinations.

\section{ACKNOWLEDGMENTS}

Financial support was provided by Intervet International, Schering-Plough Animal Health, and Dairy Farmers of Ontario. We are grateful to all the participating dairy producers for their time and interest. Particular thanks are due to Jeromy TenHag and Jodi Wallace for excellent assistance with data management. We thank Drs. R. Bell, R. Dingwell, J. Jansen, D. Kelton, K. Lissemore, P. Menzies, D. Sandals, R. Swackhammer, J. Wichtel, and J. VanLeeuwen for enrolling and examining cows for the study.

\section{REFERENCES}

Bartlett, P. C., J. H. Kirk, M. A. Wilke, J. B. Kaneene, and E. C. Mather. 1986. Metritis complex in Michigan Holstein-Friesian cattle: incidence, descriptive epidemiology and estimated economic impact. Prev. Vet. Med. 4:235-248.

Bergstralh, E., J. Kosanke, and T. Therneau. 1993. SAS Macro PHLEV: leverage residuals matrix for proportional hazard regression. Mayo Clinic Tech. Rep. 58, Mayo Clinic, Rochester, MN.

Bondurant, R. H. 1999. Inflammation in the bovine female reproductive tract. J. Dairy Sci. 82(Suppl. 2):101-110.

Bonnett, B. N., S. W. Martin, and A. H. Meek. 1993. Associations of clinical findings, bacteriological and histological results of endometrial biopsy with reproductive performance of postpartum dairy cows. Prev. Vet. Med. 15:205-220.

Collett, D. 1994. Modelling Survival Data in Medical Research. Chapman and Hall, London, United Kingdom.

Correa, M. T., H. Erb, and J. Scarlett. 1993. Path analysis for seven postpartum disorders of Holstein cows. J. Dairy Sci. 76:13051312.

Curtis, C. R., H. N. Erb, C. J. Sniffen, R. D. Smith, and D. S. Kronfeld. 1985. Path analysis of dry period nutrition, postpartum metabolic and reproductive disorders, and mastitis in Holstein cows. J. Dairy Sci. 68:2347-2360.

Dohmen, M. J. W., J. A. C. M. Lohuis, G. Huszenicza, P. Nagy, and M. Gacs. 1995. The relationship between bacteriological and clinical findings in cows with subacute/chronic endometritis. Theriogenology 43:1379-1388.

Dohoo, I. R., S. W. Martin, and A. H. Meek. 1983. Disease, production, and culling in Holstein-Friesian cows. I. The data. Prev. Vet. Med. 1:321-334.

Dijkhuizen, A. A., J. Stelwagen, J. A. Renkema. 1985. Economic aspects of reproductive failure in dairy cattle. I. Financial loss at the farm level. Prev. Vet. Med. 3:251-263.

Emanuelson, U., P. A. Oltenacu, and Y. T. Grohn. 1993. Nonlinear mixed model analyses of five production disorders of dairy cattle. J. Dairy Sci. 76:2765-2772.

Erb, H. N. and S. W. Martin. 1980. Interrelationships between production and reproductive diseases in Holstein cows. Data. J. Dairy Sci. 63:1911-1917.

Erb, H. N., R. D. Smith, R. B. Hillman, P. A. Powers, M. C. Smith, M. E. White, and E. G. Pearson. 1984. Rates of diagnosis of six 
diseases of Holstein cows during 15-day and 21-day intervals. Am. J. Vet. Res. 45:333-335.

Erb, H. N., R. D. Smith, P. A. Oltenacu, C. L. Guard, R. B. Hillman, P. A. Powers, M. C. Smith, and M. E. White. 1985. Path model of reproductive disorders and performance, milk fever, mastitis, milk yield, and culling in Holstein cows. J. Dairy Sci. 68:33373349 .

Etherington, W. G., S. W. Martin, I. R. Dohoo, and W. T. Bosu. 1985. Interrelationships between ambient temperature, age at calving, postpartum reproductive events, and reproductive performance in dairy cows: a path analysis. Can. J. Comp. Med. 49:254-260.

Ferguson, J. D., and D. T. Galligan. 1999. Veterinary Reproductive Programs. Pages 131-137 in Proc. 32nd Annu. Conf. Am. Assoc. Bovine Pract.

Ferguson, J. D., and D. T. Galligan. 2000. Assessment of Reproductive Efficiency in Dairy Herds. Compend. Contin. Educ. Proc. Vet. 22:S150-S158.

Fonseca, F. A., J. H. Britt, B. T. McDaniel, J. C. Wilk, and A. H. Rakes. 1983. Reproductive traits of Holsteins and Jerseys. Effects of age, milk yield, and clinical abnormalities on involution of the cervix and uterus, ovulation, estrous cycles, detection of estrus, conception rate, and days open. J. Dairy Sci. 66:1128-1147.

Fourichon, C., H. Seegers, N. Bareille, and F. Beaudeau. 1999. Effects of disease on milk production in the dairy cow: a review. Prev. Vet. Med. 41:1-35.

Fourichon, C., H. Seegers, and X. Malher. 2000. Effect of disease on reproduction in the dairy cow: a meta-analysis. Theriogenology. 53:1729-1759.

Gier, H. T., and G. B. Marion. 1968. Uterus of the cow after parturition: involutional changes. Am. J. Vet. Res. 29:83-96.

Gilbert, R. O., and W. S. Schwark. 1992. Pharmacologic considerations in the management of peripartum conditions in the cow. Vet. Clin. North Am. Food. Anim. Pract. 8:29-56.

Gilbert, R. O. 1997. Bovine endometritis, a continuing enigma. Pages 207-219 in Proc. Cornell Annu. Conf., Cornell Univ., Ithaca, NY.

Grohn, Y. T., H. N. Erb, C. E. McCullogh, and H. S. Saloniemi. 1989. Epidemiology of metabolic disorders in dairy cattle: associations among host characteristics, disease, and production. J. Dairy Sci. 72:1876-1885.

Grohn, Y. T., S. W. Eicker, V. Ducrocq, and J. A. Hertl. 1998. Effect of diseases on the culling of Holstein dairy cows in New York State. J. Dairy Sci. 81:966-978.

Heuwieser, W., B. A. Tenhagen, M. Tischer, J. Luhr, and H. Blum. 2000. Effect of three programmes for the treatment of endometritis on the reproductive performance of a dairy herd. Vet. Rec. 146:338-341.

Kelton, D. F., K. E. Leslie, W. G. Etherington, B. N. Bonnett, and J. S. Walton. 1991. Accuracy of rectal palpation and of a rapid milk progesterone enzyme immunoassay for determining the presence of a functional corpus luteum in subestrous dairy cows. Can. Vet. J. 32:286-291.

LeBlanc, S. J., T. F. Duffield, K. E. Leslie, K. G. Bateman, G. P. Keefe, J. S. Walton, W. H. Johnson, and W. A. King. 2002. The effect of treatment of clinical endometritis on reproductive performance in dairy cows. J. Dairy Sci. 85:2237-2249.

Lee, L. A., J. D. Ferguson, and D. T. Galligan. 1989. Effect of disease on days open assessed by survival analysis. J. Dairy Sci. 72:1020-1026.

Leslie, K. E. 1983. The events of normal and abnormal postpartum reproductive endocrinology and uterine involution in dairy cows: a review. Can. Vet. J. 24:67-71.

Lewis, G. S. 1997. Uterine health and disorders. J. Dairy Sci. 80:984-994.

Madej, A., H. Kindahl, W. Woyno, L. E. Edqvist, and R. Stupnicki. 1984. Blood levels of 15-keto-13,14-dihydro-prostaglandin F2 $\alpha$ during the postpartum period in primiparous cows. Theriogenology. 21:279-287.

Martin, S. W., A. H. Meek, and P. Willeberg. 1987. Veterinary Epidemiology-Principles and Methods. Iowa State Univ. Press, Ames, IA.

McDermott, J. J., Y. H. Schukken, and M. M. Shoukri. 1994. Study design and analytic methods for data collected from clusters of animals. Prev. Vet. Med. 18:175-191.

Miller, H. V., P. B. Kimsey, J. W. Kendrick, B. Darien, L. Doering, C. Franti, and J. Horton. 1980. Endometritis of dairy cattle: diagnosis, treatment, and fertility. Bovine Practitioner. 15:13-23.

Morrow, D. A., S. J. Roberts, K. McEntee, and H. G. Gray. 1966. Postpartum ovarian activity and uterine involution in dairy cattle. J. Am. Vet. Med. Assoc. 149:1596-1609.

Oltenacu, P. A., J. H. Britt, R. K Braun, and R. W. Mellenberger. 1983. Relationships among type of parturition, type of discharge from genital tract, involution of cervix, and subsequent reproductive performance in Holstein cows. J. Dairy Sci. 66:612-619.

Oltenacu, P. A., A. Frick, and B. Lindhe. 1990. Epidemiological study of several clinical diseases, reproductive performance and culling in primiparous Swedish cattle. Prev. Vet. Med. 9:59-74.

Plazier, J. C. B., G. J. King, J. C. M. Dekkers, and K. Lissemore. 1997. Estimation of economic values of indices for reproductive performance in dairy herds using computer simulation. J. Dairy Sci. 80:2775-2783.

Radostitis, O. M., K. E. Leslie, and J. Fetrow. 1994. Herd HealthFood Animal Production Medicine, 2nd ed. W.B. Saunders Co., Philadelphia, PA.

Rothman, K. J., and S. Greenland. 1998. Modern Epidemiology. 2nd ed., Lippincott Williams \& Wilkins, Philadelphia, PA.

SAS User's Guide: Statistics, Version 8 Developer's Edition. 1999. SAS Inst., Inc., Cary, NC.

Sandals, W. C., R. A. Curtis, J. F. Cote, and S. W. Martin. 1979. The effect of retained placenta and metritis complex on reproductive performance in dairy cattle-a case control study. Can. Vet. J. 20:131-135.

Semambo, D. K. N., T. R. Ayliffe, J. S. Boyd, and D. J. Taylor. 1991. Early abortion in cattle induced by experimental intrauterine infection with pure cultures of Actinomyces pyogenes. Vet. Rec. 129:12-16.

Shoukri, M. M., and C. A. Pause. 1999. Statistical Methods for the Health Sciences. 2nd ed. CRC Press, Boca Raton, FL.

Stevenson, J. S., and E. P. Call. 1988. Fertility of postpartum dairy cows after administration of gonadotropin-releasing hormone and prostaglandin F2alpha: a field trial. J. Dairy Sci. 71:1926-1933.

Studer, E., and D. A. Morrow. 1978. Postpartum evaluation of bovine reproductive potential: comparison of findings from genital tract examination per rectum, uterine culture, and endometrial biopsy. J. Am. Vet. Med. Assoc. 172:489-494.

Tenhagen, B. A., and W. Heuwieser. 1999. Comparison of a conventional reproductive management programme based on rectal palpation and uterine treatment of endometritis with a strategic prostaglandin F2 alpha programme. J. Vet. Med. A 46:167-176.

Therneau, T. 1993. Using a multiple events Cox model. Pages 114 in Proc. Biometrics Section Am. Stat. Assoc. Mtg., Hamilton, ON, Canada.

Thurmond, M. C., C. M. Jameson, and J. P. Picanso. 1993. Effect of intrauterine antimicrobial treatment in reducing calving-toconception interval in cows with endometritis. J. Am. Vet. Med. Assoc. 203:1576-1578.

Youngquist, R. S., and M. D. Shore. 1997. Postpartum uterine infections. Pages 335-340 in Current Therapy in Large Animal Theriogenology. R. S. Youngquist, ed. W. B. Saunders Co., Philadelphia, PA. 